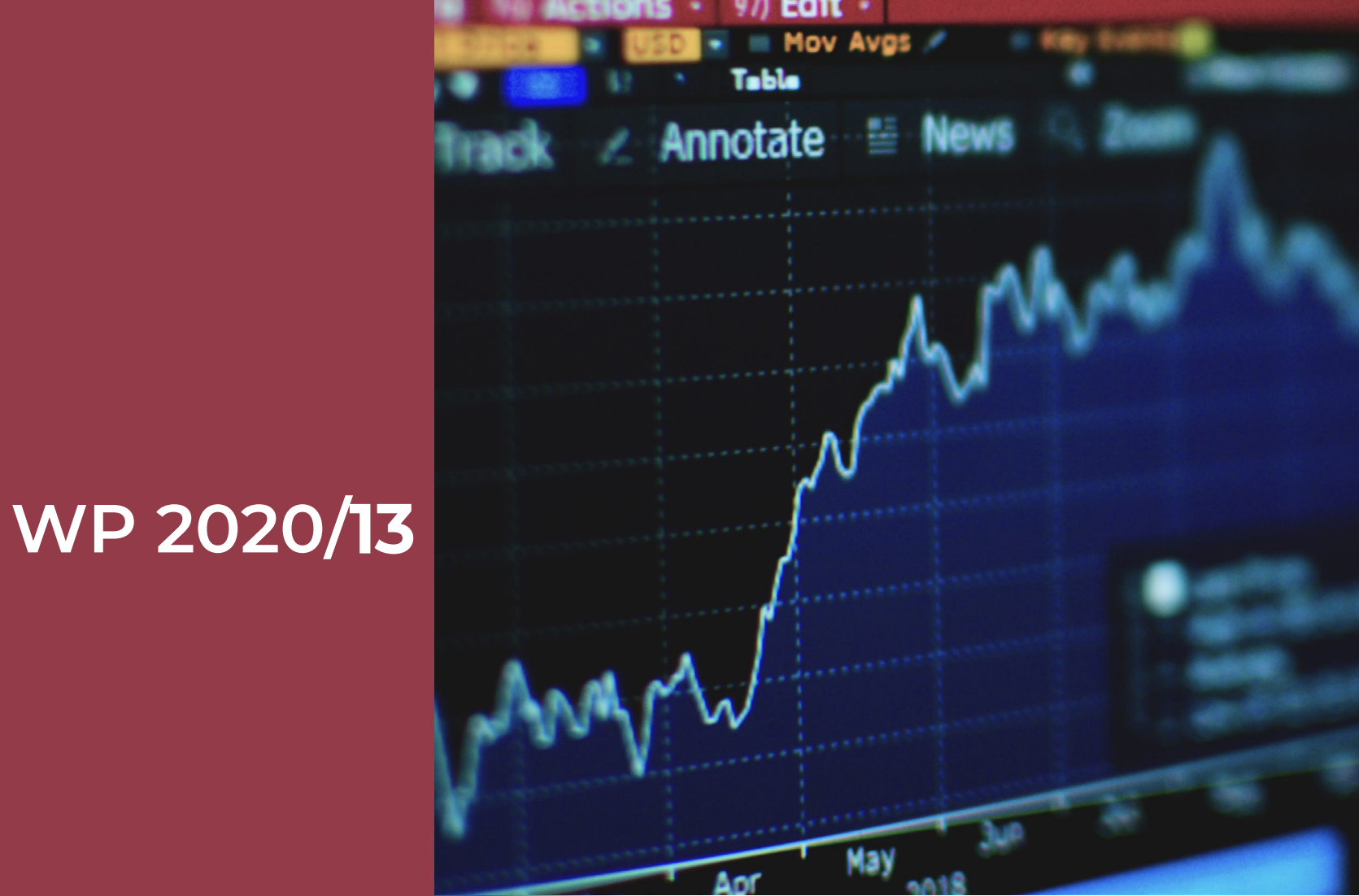

Catherine D'Hondt, Younes Elhichou Elmaya, Mikael Petitjean

Retail Investing in Passive Exchange Traded Funds 


\section{LFIN}

Voie du Roman Pays 34, L1.03.01

B-1348 Louvain-la-Neuve

Tel (32 10) 474304

Email: lidam-library@uclouvain.be

https:/uclouvain.be/en/research-institutes/

lidam/lfin/working-papers.html 


\title{
Retail Investing in Passive Exchange Traded Funds*
}

\author{
Catherine D’Hondt $\dagger^{\text {Younes Elhichou Elmaya }{ }^{\ddagger} \text { Mikael Petitjean }}{ }^{\S}$
}

January 21, 2020

\begin{abstract}
Using a large set of trading accounts, we study the determinants of retail investing in passive Exchange Traded Funds (P-ETFs). Controlling for investor characteristics related to their risk-return profile, trading activity, and socio-demographics, we show that the probability and magnitude of P-ETF investing by retail investors can be explained by financial knowledge, financial experience, and behavioral biases such as overconfidence and local bias. We also show that the more active P-ETF users hold a lower number of stocks and modify the composition of their stock portfolio less extensively, pointing to a substitution effect between stocks and P-ETFs.
\end{abstract}

Keywords: Behavioral biases, ETFs, Financial literacy, Passive investing, Retail investors.

JEL classification: G11, G40, G53

\footnotetext{
${ }^{*}$ The authors are grateful to the brokerage house for providing the data. Any errors are the full responsibility of the authors.

${ }^{\dagger}$ Louvain Finance (LIDAM), Louvain School of Management.

${ }^{\ddagger}$ Louvain Finance (LIDAM), Louvain School of Management. Corresponding author. Email: younes.elhichou@uclouvain.be - Address: Chaussée de Binche 151, 7000 Mons, BELGIUM Tel: +32 (0)65 323441.

${ }^{\S}$ IÉSEG School of Management (LEM UMR 9221 CNRS) and Louvain Finance (LIDAM), Louvain School of Management.
} 


\section{Introduction}

Since the seminal work of Markowitz in 1952 diversification has become one of the cornerstones of modern finance. Most investors even consider it as "the only free lunch in finance" (Choueifaty and Coignard, 2008). This explains the very significant expansion of mutual funds over the years. Compared to mutual funds, passive Exchange Traded Funds (P-ETFs hereafter) have emerged more recently and have helped investors better diversify their portfolios at low cost. Over the last two decades, ETFs have become very popular, breaching the threshold of $\$ 5$ tn in assets under management in July 2018.

In the literature, there are many more empirical studies on the use of mutual funds by retail investors. For example, Capon et al. (1996), Alexander et al. (1998) and Barber et al. (2005) find that retail investors who trade mutual funds often undervalue both the risks and costs associated with active portfolio management. Only a few papers address retail ETF investing. Bhattacharya et al. (2017) investigate whether individual investors in Germany benefit from using ETFs. Compared to non-users, they find that ETF users are younger, wealthier (in terms of both portfolio value and overall wealth), and have a shorter relationship with the broker. Davydov et al. (2017) bring evidence that investors perform better when they invest in mutual funds, although younger investors are more skillful in trading Exchange Traded Products (ETPs). ${ }^{1}$

Although retail investors have a much easier access to well-diversified low-cost funds than in the past, very little is known about the determinants of retail investing in P-ETFs. To the best of our knowledge, we know close to nothing about the typical retail investor in P-ETFs. This is all the more surprising in light of the fact that most scholars are convinced that P-ETFs are the most suitable equity products available to retail investors.

In this paper we fill the gap by analyzing the drivers of P-ETF retail investing, ${ }^{2}$ with a particular focus on financial knowledge, financial experience, and behavioral biases. Our sample includes a very large set of retail trading accounts: 26,140 retail investors, to be precise. The time period ranges from January 2003 to March 2012. In addition to trading

\footnotetext{
${ }^{1}$ ETPs include ETFs, ETCs (Exchange Traded Commodities), and ETNs (ExchangeTraded Notes).

${ }^{2}$ We investigate only passive ETFs, i.e. ETFs that track an asset (or a basket of assets). Hence, we exclude leveraged, inverse, or leveraged-inverse ETFs, i.e. ETFs that have a multiplier different from 1.
} 
records, we match individual socio-demographics and subjective characteristics, which are survey-based data collected by the brokerage house within the context of the MiFID regulation that came into force in November 2007 in the EU member states. ${ }^{3}$ Using the data at hand, we create four sets of potential determinants of the use of P-ETFs: socio-demographic variables (i.e. gender, age, education, language), objective measures of trading activity (such as experience and stock portfolio size), subjective variables based on survey-data (among which target return, risk aversion and financial knowledge) and behavioral variables (such as proxies for overconfidence, lack of diversification, and local bias). We include these four sets of explanatory variables in a zero-inflated negative binomial (ZINB) regression model, which enables us not only to explain the probability of investing in P-ETFs but also to identify the investor's characteristics that drive the magnitude of P-ETF investing.

Our main findings may be summarized as follows. Retail investors who are more likely to invest in P-ETFs are those who are better educated, self-report both higher financial knowledge and longer investment horizon, exhibit longer trading experience, hold a more diversified stock portfolio, and trade these stocks more intensively. On the contrary, retail investors who aim at a higher target return, suffer from either overconfidence or the local bias, are less likely to invest in P-ETFs.

When focusing only on the retail investors who trade P-ETFs, we find that trading activity in P-ETFs is also boosted by higher education, better self-reported financial knowledge, a longer investment horizon, a lower target return, and stronger trading experience. The most active P-ETF retail investors are also older and are less subject to the local bias. Most interestingly, a trade-off seems to exist among P-ETF users between the magnitude of their P-ETF investing and the magnitude of their stock investing. The users who trade ETFs more actively hold a lower number of stocks and modify the composition of their stock portfolio less extensively. This points to a substitution effect between stocks and P-ETFs as trading in P-ETFs increases.

The rest of the paper is organized as follows. In Section 2, we review the relevant

\footnotetext{
${ }^{3}$ MiFID stands for the Markets in Financial Instruments Directive. MiFID I (2004/39/EC) is known as the first version of this Directive while a review of it was implemented in January 2018 (known as MiFID II $(2014 / 65 / \mathrm{UE}))$. For more details on the MiFID regulation, please visit the European Commission website (http://ec.eurosopa.eu/internal_market/securities/isd/mifid2/index_en.htm).
} 
literature and formulate six hypotheses regarding the determinants of retail investing in PETFs. Section 3 describes our data and provides descriptive statistics for the four set of variables under scrutiny. We present our empirical results in Section 4 and we conclude in Section 5 .

\section{Related literature and hypotheses}

The objective of this study is to identify all the key determinants of retail investing in P-ETFs, controlling for socio-demographic factors, risk-return characteristics, and trading activity variables (as detailed in Section 3). The central hypotheses that we propose to test in our model are whether the use of P-ETFs by retail investors can be explained by financial knowledge, financial experience, and behavioral biases. The importance we give to these factors is justified by the widely-documented impact that they can have on wealth and social welfare in general.

\subsection{Financial knowledge and retail investing in P-ETFs}

There is ample evidence that financial knowledge benefits investors. Baker and Nofsinger (2002) show that financial knowledge helps reduce the negative effect of behavioral biases on wealth. Hilgert et al. (2003) identify a significant correlation between financial knowledge and day-to-day financial management abilities. Lusardi and Mitchell (2007) show that individuals with low financial knowledge are less likely to engage in successful retirement planning. Gaudecker (2015) find that households who are more financially knowledgeable achieve desirable investment outcomes, such as a reduced probability of being underdiversified.

Two approaches are usually used to evaluate the level of financial knowledge of retail investors. The first approach is based on objective measures while the second one relies on subjective measures. Objective measures are typically based on a set of technical and numerical questions used to formally assess how people deal with fundamental concepts at the root of saving and investment decisions. By contrast, subjective financial knowledge relies on questions asking people to self-assess their financial knowledge. 
Babiarz and Robb (2014) who combine both types of measure show that households whose financial knowledge is stronger are more likely to save adequately and cover 3 months of typical expenses. Even if there is no consensus on the correlation level between objective and subjective measures, most studies find a strong positive relationship between objective and subjective measures of financial knowledge (e.g. Van Rooij et al., 2011). There are exceptions to the rule, like Lusardi and Mitchell (2011) who point to a rather weak relationship. Subjective financial knowledge is nevertheless one of the most significant factors in determining the way people invest (Courchane and Zorn (2005)). Most interestingly, Bellofatto et al. (2018) find that investors who report higher levels of subjective financial literacy seem to invest in a smarter way, displaying higher gross and net returns as well as higher excess Sharpe ratios. They also seem to be less prone to the disposition effect and tend to achieve diversification by investing in funds.

Financial knowledge is also a robust determinant of the awareness about investment alternatives. For example, Bellofatto et al. (2018) show that investors who report higher levels of financial literacy are more likely to invest in funds. Using survey data, Müller and Weber (2010) show evidence that there is a positive relationship between financial literacy and the probability of investing passively. Finally, Enete et al. (2018) find that ETF-users have a higher (subjective or objective) financial knowledge, compared to non-users of ETFs.

Based on these findings, we formulate two hypotheses that we can directly test in the ZINB model developed in Section 4.

H1. The more financially knowledgeable the retail investors, the more likely they invest in P-ETFs.

H1*. Those among P-ETF retail investors who are more financially knowledgeable trade them more actively.

\subsection{Financial experience and retail investing in P-ETFs}

In addition to financial knowledge, experience is another key element in the decisionmaking process of investing, as documented by Feng and Seasholes (2005) who find that trading experience eliminates the reluctance of retail investors to realize losses. In the same 
vein, Lyons et al. (2006) show that experience could positively influence financial behavior while Nicolosi et al. (2009) bring evidence that individual investors learn from their trading experience. Using survey data, Wang (2011) find that experience (besides knowledge and income) is an important factor influencing the way younger generations invest in mutual funds. Bailey et al. (2011) report that sophisticated investors, i.e. better informed, higher income, older, and more experienced investors, make good use of mutual funds, hold a high proportion of funds for long periods of time, avoid high expense funds, and experience relatively good performance.

Based on the aforementioned findings, we expect financial experience to be positively correlated with retail investing in P-ETFs. Hence, we formulate our next hypotheses as follows.

H2. The more experienced the retail investors, the more likely they invest in P-ETFs.

H2* Those among P-ETF retail investors who display longer experience trade them more actively.

\subsection{Behavioral biases and retail investing in P-ETFs}

Behavioral biases lead to costly investment mistakes among individual investors, as documented by Singh (2010) and Ramiah et al. (2015). The claim that a majority of individuals suffer from overconfidence is well-documented in the literature (Fischoff, 1982; Moore and Healy, 20018; De Bondt and Thaler, 1995; and Camerer and Lovallo, 1999). Carpentier and Suret (2011) show that overconfident investors own riskier portfolios on average. ${ }^{4}$ Another noticeable consequence of overconfidence is overtrading (Odean, 1999).

Bailey et al. (2011) find that overconfident investors are more likely to select higher expense funds and avoid index funds. Moreover, when overconfident investors buy mutual funds, they trade them frequently and prefer active funds with high expense ratios rather than passive index funds with low expense ratios such as ETFs. Consistent findings are reported in Davydov et al. (2017).

\footnotetext{
${ }^{4}$ According to these authors, overconfident investors have a tendency to attribute their success to their own skills while they tend to attribute their failures to circumstances beyond their control or to bad luck.
} 
Consequently, we expect that P-ETFs are not targeted by overconfident investors, which leads to hypotheses $\mathrm{H} 3$ and $\mathrm{H} 3{ }^{*}$.

H3. Overconfident retail investors are less likely to invest in P-ETFs

H3*. Those among P-ETF retail investors who are overconfident trade them less actively.

Narrow framing is another behavioral bias implying that investors tend to select investments individually, instead of considering the broad impact on their portfolio. Kumar (2009) finds that there is a positive relationship between uncertainty and narrow framing, i.e. investors are more likely to adopt focused and narrower decision frames in more uncertain environments. Liu et al. (2010) show that the professionalism of traders, sophistication, and trading experience are negatively correlated with the degree of narrow framing. Focusing on investing in mutual funds, Bailey et al. (2011) find that investors who exhibit higher scores of narrow framing are less likely to invest in equity mutual funds and index funds. This suggests that P-ETF users may have broader views about investing and financial markets, and then suffer less from narrow framing. Accordingly, we formulate two more hypotheses as follows.

H4. Retail investors who suffer from narrow framing are less likely to invest in P-ETFs.

H4*. Those among P-ETF retail investors who suffer from narrow framing trade them less actively.

Lack of diversification among retail investors is also well-established in the literature. The majority of individual investors and households typically own only a few stocks in their portfolios (Kelly, 1995; Polkovnichenko, 2005). This lack of diversification negatively affects the financial well-being (Barber and Odean, 2000). Goetzmann and Kumar (2008) find that the degree of sophistication of investors determine the level of diversification of their portfolios.

While transaction costs have been traditionally mentioned as one of the major drivers of the lack of diversification (Evans and Archer, 1968), this explanation is no longer relevant with the emergence of ETFs and index funds, which has allowed for a drastic reduction 
in transaction costs (Domian et al., 2007). P-ETF users are expected to be more aware about diversification principles than non-users since P-ETFs are de facto cheap diversification tools at the disposal of investors. We therefore expect non-users of P-ETFs to apply the diversification principle in their stock portfolio less often than P-ETF users. The same reasoning may apply to the population of P-ETF retail investors: those among P-ETF users whose stock portfolio is underdiversified may trade P-ETFs less extensively. This leads us to hypotheses $\mathrm{H} 5$ and $\mathrm{H} 5 *$ :

H5. Retail investors whose stock portfolio is underdiversified are less likely to invest in P-ETFs

H5*. Those among P-ETF retail investors whose stock portfolio is underdiversified trade P-ETFs less actively.

A particular case of underdiversification is the local bias, i.e. when investors only include stocks from one region (most of the time, close to them) within their portfolio. Bailey et al. (2011) find that investors have preferences for companies that are geographically close to their home country. The same result is documented in Massa and Simonov (2006), who point to reasons related to geographical and professional proximities (Boyle et al. (2012)). Building on these findings, we expect a negative relationship between P-ETF investing (or its magnitude) and the local bias. Hence, we state our two last hypotheses as follows.

H6. Retail investors who suffer from the local bias are less likely to invest in P-ETFs.

H6* Those among P-ETF retail investors who suffer from the local bias trade P-ETFs less actively.

\section{Data and sample}

\subsection{Data}

Our data come from an online Belgian brokerage house. They are made of two datasets. The first dataset provides information about the trading activity of 26,140 retail investors 
over the period January 2003-March 2012. For each investor, we have detailed trading records (ISIN code, time-stamp, trade direction, executed quantity, trade price, explicit transaction costs, etc.). We count 22,376 trades on P-ETFs, involving 3,484 retail investors (i.e. 13.33\% of the retail investors). These P-ETF users trade 313 different P-ETFs, among which 196 on equities and 72 on commodities. ${ }^{5}$

The second dataset provides matched individual data that we classify as either sociodemographic or survey-based. Socio-demographic variables include age, gender, education and spoken language. The survey-based data are subjective investor characteristics ${ }^{6}$ col- $^{-}$ lected by the brokerage house within the context of the European MiFID regulation. In short, this piece of regulation has made it compulsory for investment firms to collect specific information about their retail clients' needs and preferences. Accordingly, investment firms operating in the EU are obliged to submit questionnaires (that are then referred to as "MiFID tests") to their clients. Specifically, two tests have emerged: (1) the Appropriateness test (hereafter the A-test), and (2) the Suitability test (hereafter the S-test). Investors who ask for order execution on "complex" instruments have only to fulfill the A-test. This test aims at ensuring that the investor has the necessary experience and knowledge to understand the risks involved in these "complex" financial instruments. Investors who ask for financial advice and/or portfolio management services have to fulfill the S-test, which aims at assessing their level of knowledge and experience, their investment objectives as well as their financial capacity. ${ }^{7}$

For the purpose of this study, we make a distinction between "subjective" variables, which are based on the aforementioned A-test and S-test, and "objective" variables, which characterize the trading activity of retail investors. In addition, we build some behavioral variables, i.e. proxies used to characterize overconfidence, narrow framing, lack of diversifica-

\footnotetext{
${ }^{5}$ More information about the P-ETFs in our sample are provided in Table 8 and Table 9 in the Appendix.

${ }^{6}$ These survey data are reported online by each investor. Answers are self-reported decisions that investors make on their own, without any interaction with a financial intermediary. Since most of these data imply self-assessment, we consider them as subjective characteristics.

${ }^{7}$ Such items are usually covered in Investment Policy Statements (IPS) used in portfolio management delegation. There are some points according to Boone and Lubitz (2004) that are primordial for an IPS: 1) client goals and objectives, 2) client fears and concerns, 3) investment time frame, 4) expected outside mortality, 5) retirement time frame, 6) shorter-term financial needs, 7) risk tolerance attitudes, and 8) risk capacity. In our data, the S-test almost covers all those points.
} 
tion, and local bias. Descriptive statistics about socio-demographic and subjective variables are provided in Subsection 3.2.1 and 3.2.2, respectively. Objective variables are presented in Subsection 3.2.3 while behavioral variables are described in Subsection 3.2.4.

\subsection{Descriptive statistics}

Following Bhattacharya et al. (2017) and Bailey et al. (2011), we classify as a P-ETF user any investor who traded a P-ETF at least once over the 2003-2012 period. In order to come out with workable data, we use age and trading experience as filters. Hence, we exclude both less than 10-year-old investors and above 110-year-old investors. We also exclude investors with less than 5-month trading experience in order to disregard very short-lived investors, as in Bellofatto et al. (2018) and Glaser and Weber (2009).

\subsubsection{Socio-demographic variables}

The set of socio-demographic attributes includes age, gender, education and spoken language. ${ }^{8}$ We build dummy variables for gender (dummy variable equal to 1 if the investor is a male), education (dummy variable equal to 1 if the investor holds a university degree or equivalent) and language (dummy variable for each language: French, Dutch, or English). All these variables are used as control variables in the ZINB regression model used in Section 4 .

Table 1 reports summary statistics for our socio-demographic variables, with a distinction between P-ETF users and non-users. First, P-ETF users are older than non- users on average (50.32 for P-ETF users versus 47.91 for non-users). Second, the proportion of males is similar in the two subsamples, i.e. $87 \%$ among P-ETF users versus $86 \%$ among nonusers. Although statistically significant at the $5 \%$ level, this difference is negligible. As far as education is concerned, the proportion of investors who hold a university degree or equivalent is significantly larger among P-ETF users (80\% versus 69\%). Regarding spoken language, the proportion of Dutch speakers is higher among non-users of P-ETFs (53\% versus

\footnotetext{
${ }^{8}$ Belgium has three official languages: French, Dutch and German. French and Dutch are spoken the most. On the online brokerage trading platform, investors can choose from three available languages: French, Dutch and English.
} 
$51 \%)$. On the contrary, the proportion of English speakers is higher among P-ETF users than among non-users (7\% versus 5\%). The proportion of French speakers is exactly the same $(42 \%)$ in both subsamples.

Table 1: Descriptive statistics - socio-demographic variables

\begin{tabular}{|c|c|c|c|c|c|c|c|c|}
\hline \multirow{2}{*}{ Metrics } & & \multicolumn{3}{|c|}{ P-ETF users } & \multicolumn{3}{|c|}{ non-users } & \multirow[b]{2}{*}{ Diff } \\
\hline & & Mean & Std Dev & $\mathrm{N}$ & Mean & Std Dev & $\mathrm{N}$ & \\
\hline \multicolumn{9}{|c|}{ Socio-demographics } \\
\hline Age (2012) & Years & 50.32 & 13.40 & 3,484 & 47.91 & 13.24 & 22,656 & $2.41^{* * *}$ \\
\hline Gender & Dummy $=1$ if male & 0.87 & 0.33 & 3,484 & 0.86 & 0.35 & 22,656 & $0.01^{* *}$ \\
\hline Higher education & Dummy $=1$ if university & 0.80 & 0.41 & 3,484 & 0.69 & 0.46 & 22,656 & $0.11^{* * *}$ \\
\hline Dutch-speaking & Dummy $=1$ if Dutch & 0.51 & 0.50 & 3,484 & 0.53 & 0.50 & 22,656 & $0.02^{* *}$ \\
\hline French-speaking & Dummy $=1$ if French & 0.42 & 0.49 & 3,484 & 0.42 & 0.49 & 22,656 & 0.00 \\
\hline English-speaking & Dummy $=1$ if English & 0.07 & 0.26 & 3,484 & 0.05 & 0.21 & 22,656 & $0.02^{* * *}$ \\
\hline
\end{tabular}

The table reports the cross-sectional mean, standard deviation, means difference, as well as the number of investors among the P-ETF users and non-users. For each investor, we compute 'age' as the difference between 2012 and the year of birth. 'Gender' is a dummy variable equal to one if the investor is a male. 'Education' refers to the proportion of investors with a university degree or equivalent. 'Dutch-speaking', 'French-speaking' and 'English-speaking' refer to the proportion of investors who selected Dutch, French, and English, respectively, as the main language on the online trading platform. ${ }^{*}, * *, * * *$ indicate that the mean difference is statistically significant at the level of $10 \%, 5 \%$ or $1 \%$, respectively.

\subsubsection{Subjective variables}

We report the number of investors who completed the A-test and S-test in Table 2, with a distinction between P-ETF users and non-users. While all the investors have filled in the A-test, only $49.11 \%$ of them completed the S-test. $61.48 \%$ of the latter are P-ETF users.

Table 2: Number of completed A-tests and S-tests

\begin{tabular}{cccc}
\hline & Number of investors & S-test & A-test \\
\hline P-ETF users & 3,484 & 2,142 & 3,484 \\
& & $61.48 \%$ & $100.0 \%$ \\
\hline non-users & 22,656 & 10,696 & 22,656 \\
& & $47.21 \%$ & $100.0 \%$ \\
\hline Total & 26,140 & $49.11 \%$ & $100.0 \%$ \\
\hline
\end{tabular}

The table reports the number of P-ETF users and non-users as well as the number and percentage of completed A-tests and S-tests, depending on whether the investor is an P-ETF user or not.

Using the A-test, we summarize the available items into four variables, which allows to attribute for each of them a final score to each investor. We follow the same approach with 
the S-test, gathering the items into five variables again. The resulting subjective variables are presented in Table 3, in Panel A for the A-test and in Panel B for the S-test.

Table 3: Descriptive statistics - subjective variables

\begin{tabular}{|c|c|c|c|c|c|c|c|c|}
\hline \multirow[b]{2}{*}{ Metrics: Subjective variables } & & \multicolumn{3}{|c|}{ P-ETF users } & \multicolumn{3}{|c|}{ non-users } & \multirow[b]{2}{*}{ Diff } \\
\hline & & Mean & Std Dev & $\mathrm{N}$ & Mean & Std Dev & $\mathrm{N}$ & \\
\hline Panel A: Appropriateness Test & (Score Min-Max) & & & & & & & \\
\hline Knowledge of financial markets & (score $0-3$ ) & 1.72 & 0.89 & 3,484 & 1.29 & 0.97 & 22,656 & $0.43^{* * *}$ \\
\hline Knowledge of "complex" instruments & (score $0-18)$ & 7.22 & 5.78 & 3,484 & 5.32 & 5.39 & 22,656 & $1.89^{* * *}$ \\
\hline Experience with "complex" instruments & (score 0-18) & 5.96 & 5.69 & 3,484 & 4.33 & 5.16 & 22,656 & $1.63^{* * *}$ \\
\hline Awareness of the losses of "complex" instruments & (score:0-9) & 7.67 & 2.74 & 3,484 & 6.96 & 3.43 & 22,656 & $0.71^{* * *}$ \\
\hline \multicolumn{9}{|l|}{ Panel B: Suitability Test } \\
\hline Downside risk aversion & (score 1-5) & 3.99 & 0.91 & 2,142 & 3.91 & 0.95 & 10,696 & $0.08^{* * *}$ \\
\hline Financial market and products knowledge & (score $0-7)$ & 5.01 & 1.35 & 2,142 & 4.41 & 1.43 & 10,696 & $0.60^{* * *}$ \\
\hline Investment time horizon & (score 2-11) & 8.24 & 2.44 & 2,142 & 7.51 & 2.67 & 10,696 & $0.73^{* * *}$ \\
\hline Wealth and financial situation & (score 0-17) & 9.09 & 3.58 & 2,142 & 8.07 & 3.63 & 10,696 & $1.02^{* * *}$ \\
\hline
\end{tabular}

The table presents the score interval, the cross-sectional mean, standard deviation, means difference, and number of investors among the P-ETF users and non-users. Panel A refers to the A-test while Panel B refers to the S-test. 'Knowledge of the financial markets' refers to one specific question where investors have to self-assess their knowledge of financial markets on a scale of four levels, wherein Level 0 is associated with basic knowledge while Level 3 refers to an experienced investor "who manages any aspect of the financial markets'. For 'Knowledge of "complex" instruments', 'Experience for "complex" instruments' and 'Awareness of the losses of "complex" instruments', the score of each variable can be seen as the investor's self-assessment regarding his/her own abilities and skills. For example, a score of 18 out of 18 for the variable Knowledge of "complex" instruments means that the investor considers himself/herself as an expert in the field. Conversely, a score of 0 (out of 18) means that the investor declares no knowledge about "complex" instruments. For 'Downside risk aversion', 'Financial market and products knowledge', 'Investment time horizon' and 'Wealth and financial situation', the score of each variable can be seen as the investor's direct self-assessment regarding the item. ${ }^{*}, * *, * *$ indicate that the mean difference is statistically significant at the level of $10 \%, 5 \%$ or $1 \%$, respectively.

Panel A of Table 3 shows that P-ETF users display a higher financial literacy than nonusers. This holds for both the knowledge of financial markets in general and the knowledge, experience and awareness of "complex" instruments in particular. For example, the mean score of P-ETF users regarding the variable 'Knowledge of the financial markets' is 1.72 while the corresponding mean for non-users is only 1.29. Moreover, P-ETF users (1) have a relatively higher knowledge when compared to non-users (7.22 vs 5.32); (2) have more experience with "complex" instruments (5.96 vs 4.33); and (3) are more aware (7.67 vs 6.96) of the risk associated with trading "complex" instruments (in particular potential losses). All these differences are statistically significant at the $1 \%$ level. $^{9}$

In Panel B of Table 3, P-ETF users exhibit on average a higher 'Downside risk aversion' than non-users (3.99 vs 3.91). Consistent with Panel A, P-ETF users also display a better financial literacy, compared to non-users. In addition, P-ETF users have a higher average

\footnotetext{
${ }^{9}$ For subjective variables, we opt for Wilcoxon signed-rank tests, which are an appropriate non-parametric alternative to the t-test.
} 
score for both 'Investment time horizon' and 'Wealth and financial situation'. This means that P-ETF users are, on average, wealthier and have a longer investment horizon, compared to non-users.

Table 4 reports the proportion of investors across the different investment profiles. ${ }^{10}$ The proportion of P-ETF users who are conservative $(1.87 \%)$ or neutral $(14.66 \%)$ is lower, compared to non-users $(2.60 \%$ and $24.75 \%$, respectively). Correspondingly, the proportion of P-ETF users who are dynamic $(65.36 \%)$ or aggressive $(18.11 \%$ ) is higher (about $61.91 \%$ and $10.74 \%$, respectively). All these differences are statistically significant at the $1 \%$ level, except for the conservative profile (significant at $5 \%$ ).

Table 4: Frequencies - investment profile

\begin{tabular}{cccl}
\hline & P-ETF users & non-users & Diff \\
\hline Conservative & 40 & 278 & \\
& $1.87 \%$ & $2.60 \%$ & $-0.73 \% * *$ \\
\hline Neutral & 314 & 2,647 & \\
& $14.66 \%$ & $24.75 \%$ & $-10.09 \% * * *$ \\
\hline Dynamic & 1,400 & 6,622 & \\
& $65.36 \%$ & $61.91 \%$ & $3.45 \% * * *$ \\
\hline Aggressive & 388 & 1,149 & \\
& $18.11 \%$ & $10.74 \%$ & $7.37 \% * * *$ \\
\hline Total & 2,142 & 10,696 & \\
\hline The table reports the empirical frequencies and the proportions of investors
\end{tabular}

The table reports the empirical frequencies and the proportions of investors depending on their investment profile, with a distinction between P-ETF users and non-users. The classification of each investor is based on his/her final score in the S-test. $*, * *, * * *$ indicate that proportions statistically differ at the level of $10 \%, 5 \%$ or $1 \%$, respectively.

\subsubsection{Objective variables}

Using the trading data, we first rebuild end-of-month individual portfolios and then compute a set of "objectives" variables, aiming at characterizing each investor' trading activity on stocks. In particular, we compute the following variables for each investor: (1) number of stock trades over the whole sample period; (2) trading experience in months, counted as

\footnotetext{
${ }^{10}$ The investment profile is based on the investor's final score in the S-test.
} 
the number of months between the first and last trades on stocks; ${ }^{11}$ (3) number of different stocks traded (NDST) over the sample period; ${ }^{12}$ (4) trade duration computed as the average number of days between two consecutive trades on stocks; ${ }^{13}$ (5) average number of stocks held in end-of-month portfolios; (6) stock trading intensity (STI), which is a dummy variable equal to one if the investor's monthly portfolio turnover is in the upper quartile of the sample and zero otherwise, ${ }^{14}$ and (7) underperformance on stocks (UPS), which is equal to one when the investor's net excess Sharpe-ratio on stocks is in the lower quartile of the sample and zero otherwise. ${ }^{15}$

Table 5 reports cross-sectional statistics for our objective variables. Both the 'Number of stock trades' and 'Number of different stocks traded' exhibit a higher mean (almost double) for P-ETF users than non-users, i.e. 133.6 and 33.87 for P-ETF users versus only 71.94 and 17.27 for non-users. This reveals that P-ETF users trade twice more stocks and twice more different stocks in comparison with non-users. P-ETF users also exhibit a longer trading experience than non-users (56 versus 46 months). In addition, P-ETF users display a shorter trade duration on average (57 days for P-ETF users vs 91 days for non-users), suggesting P-ETF users trade stocks more frequently. Furthermore, the typical P-ETF user holds a eight-stock portfolio while the the average non-user holds a five-stock portfolio. The proportion of P-ETF users who show an intense trading activity on stocks is also lower, compared to non-users. Finally, P-ETF users are less likley to underperform the market in comparison non-users, since the proportion of those who underperform is more than 5 percentage points lower among P-ETF users than among non-users. All these differences are highly significant, both economically and statistically.

\footnotetext{
${ }^{11}$ We build on the approach of Nicolosi et al. (2009) and Bellofatto et al. (2018).

${ }^{12}$ It is an additional proxy for investor experience, based on Feng and Seasholes (2005) and Koestner et al. (2017).

${ }^{13}$ Like in D'Hondt and Roger (2017).

${ }^{14}$ Following the approach of Hoffmann et al. (2013) and Bellofatto et al. (2018), the portfolio turnover is measured as the average of the absolute values of all the purchases and sales in a particular month divided by the average of the portfolio values at the beginning and the end of this particular month. Barber and Odean (2001) and Koestner et al. (2017) also use turnover to measure what they call 'overtrading'.

${ }^{15}$ It is the net Sharpe ratio in excess of market Sharpe ratio. This performance measure is computed using the Eurostoxx 600 index as market portfolio and the 12-month Belgian T-bill rate as risk free rate.
} 
Table 5: Descriptive statistics - objective variables

\begin{tabular}{|c|c|c|c|c|c|c|c|c|}
\hline \multirow[b]{2}{*}{ Metrics } & & \multicolumn{3}{|c|}{ P-ETF users } & \multicolumn{3}{|c|}{ non-users } & \multirow[b]{2}{*}{ Diff } \\
\hline & & Mean & Std Dev & $\mathrm{N}$ & Mean & Std Dev & $\mathrm{N}$ & \\
\hline \multicolumn{9}{|l|}{ Objective Variables } \\
\hline Number of stock trades & & 133.6 & 295.5 & 3,484 & 71.94 & 161.8 & 22,656 & $61.67^{* * *}$ \\
\hline Trading experience & (in months) & 56.43 & 27.36 & 3,484 & 46.43 & 26.63 & 22,656 & $10.00^{* * *}$ \\
\hline Number of different stocks traded (NDST) & & 33.87 & 38.38 & 3,484 & 17.27 & 21.09 & 22,656 & $16.60^{* * *}$ \\
\hline Trade duration & (in days) & 57.07 & 96.40 & 3,484 & 91.12 & 158.5 & 22,656 & $-34.05^{* * *}$ \\
\hline Number of stocks & & 8.28 & 8.37 & 3,484 & 4.84 & 5.30 & 22,656 & $3.44^{* * *}$ \\
\hline Stock trading activity (STI) & Dummy $=1$ if turnover $>=Q 3$ & 0.220 & 0.414 & 3,484 & 0.245 & 0.430 & 22,656 & $-0.025^{* * *}$ \\
\hline Underperformance on stocks (UPS) & Dummy $=1$ if Net excess Sharpe-ratio $<=\mathrm{Q} 1$ & 0.203 & 0.402 & 3,484 & 0.257 & 0.437 & 22,656 & $-0.054^{* * *}$ \\
\hline
\end{tabular}

The table reports the cross-sectional mean, standard deviation, means difference, and number of investors, with a distinction between P-ETF users and non-users. 'Number of stock trades' is the total number of trades executed on stocks. 'Trading experience' is computed as the difference between the last and the first trading dates available in the sample, expressed in number of months. 'Number of different stocks traded' (NDST) is the number of different stocks traded during the whole sample period. 'Trade duration' is computed as the average number of days between two consecutive trades on stocks. 'Number of stocks' is the average number of stocks held in the end-of-month portfolio. 'Stock trading intensity' (STI) is a dummy variable which is equal to one if the investor's monthly portfolio turnover (i.e the average of the absolute values of all the purchases and sales in a particular month divided by the average of the portfolio values at the beginning and the end of this particular month) is in the upper quartile of the sample and zero otherwise. 'Underperformance on stocks' (UPS) is dummy variable which is equal to one when the investor's net excess Sharpe-ratio on stocks is in the lower quartile of the sample and zero otherwise. $*, * *, * * *$ indicate that the difference is statistically significant at the level of $10 \%, 5 \%$ or $1 \%$, respectively.

\subsubsection{Behavioral variables}

Building on the extant literature, we compute additional variables in order to capture behavioral biases. First, we estimate overconfidence with the two aforementioned objective variables measuring stock trading intensity and stock underperformance as in Odean (1999), Barber and Odean (2001), and Bailey et al. (2011). Combining both measures, we create our overconfidence proxy, which is a dummy variable equal to one when the investor simultaneously trades stocks intensively and underperforms (i.e. when the two previous dummies are set to one), and zero otherwise.

Second, we adopt the approach of Kumar and Lim (2008) and Bailey et al. (2011) by using the degree of clustering in investors' trades to measure narrow framing. ${ }^{16}$ For each investor $i$, we compute trade clustering as follows: Trade Clustering $\left(T C_{i}\right)=1-$ (number of trading days $s_{i} /$ number of trades $\left.i\right)$. However, because $T C_{i}$ is correlated with portfolio size, number of stocks, and trading frequency, we use the adjusted measure based on the peer group, ${ }^{17}$ which is computed as follows: Adjusted Trade Clustering $\left(A T C_{i}\right)=T C_{i}-$ mean trade clustering of the peer group. A positive (negative) value for $A T C_{i}$ indicates that the

\footnotetext{
${ }^{16}$ They especially identify whether an investor executes trades separately (i.e., one trade at a time) or multiple trades simultaneously.

${ }^{17} \mathrm{~A}$ peer group is made of investors who are in the same quartile in terms of portfolio size, trading frequency, and number of stocks. An investor can belong to one of the sixty four groups.
} 
trades of an investor are more (less) clustered than their counterparts who exhibit the same number of stocks, trading frequency and similar portfolio size. Based on $A T C_{i}$, we build a dummy variable to capture narrow framing $\left(N F_{i}\right)$, where the latter is equal to one when the $A T C_{i}$ is less than zero, and zero otherwise. ${ }^{18}$

Third, we use two proxies to assess underdiversification $\left(U D_{i}\right)$. $U D_{1}$, or 'Trading underdiversification', is based on the number of different stocks traded during the whole period; it reflects how broad an investor's stock trading universe is (Bellofatto et al., 2018). More specifically, we consider that an investor suffers from a lack of diversification if the number of different stocks traded during the sample period is in the lower quartile. In addition, we use the monthly average Herfindahl-Hirschman Index (HHI hereafter) to build our second proxy $U D_{2}$, or 'Portfolio weight underdiversification'. Building on Goetzmann and Kumar (2008) and Koestner et al. (2017), this index is equal to the sum of squared stock portfolio weights. It ranges from 0 for well-diversified portfolios to 1 for portfolios including only one stock. $U D_{2}$ is equal to 1 when the investor's HHI falls in the upper quartile of the sample, and zero otherwise.

Fourth, for each investor, we compute the local bias ratio, which captures the concentration of his/her trades on the Belgian stock market and the neighboring countries (France, Netherlands, Germany and Luxembourg). As in Bailey et al. (2011), ${ }^{19}$ we compute the local bias ratio as the number of trades over the full sample on companies headquartered in the home and neighboring countries (Belgium, France, Netherlands, Germany and Luxembourg) divided by the total number of trades. This ratio falls between 0 and 1 . It is equals to one when all the trades are executed in these five countries.

Table 6 reports cross-sectional statistics for our behavioral variables. First, stock trading intensity and underperformance are more prevailing among non-users than among P-ETF

\footnotetext{
${ }^{18}$ Kumar and Lim (2008) state that "a low TC measure for an investor indicates that her trades are temporally separated and thus the degree of narrow framing is likely to be higher. In particular, the tradeclustering measure is zero for investors who execute each trade on a separate day. These investors are more likely to adopt narrow decision frames in their investment choices".

${ }^{19}$ Bailey et al. (2011) use each individual's record of individual stock trades to construct a variable that captures inattention to earnings news using the formula: 1-(number of investor trades around the event)/(total number of investor trades), where "around" the event is defined as days $t-1$, $t$, and $t+1$, where $t$ is the earnings announcement date.
} 
users (25\% and $26 \%$ versus $22 \%$ and $20 \%) .{ }^{20}$ Consistently, our overconfidence proxy indicates that non-users are on average more overconfident than P-ETF users (10.5\% versus 7.2\%). Second, when looking at narrow framing, the results suggest that there is no significant difference between the two sub-samples. Third, our two proxies for underdiversification indicate that P-ETF users suffer less from this bias than non-users. The proportion of PETF users (non-users) whose number of different traded stocks belongs to the lower quartile is about $7 \%(17 \%)$. Correspondingly, the proportion of P-ETF users (non-users) whose HHI is in the upper quartile is about $14 \%$ (28\%). Finally, the average local bias ratio is slightly higher among non-users than among P-ETF users (0.750 versus 0.725$)$. This suggests that the trades executed by non-users are more locally concentrated than those completed by P-ETF users. All these differences are statistically significant at the $1 \%$ level.

Table 6: Descriptive statistics - behavioral variables

\begin{tabular}{|c|c|c|c|c|c|c|c|c|}
\hline \multirow{2}{*}{ Metrics } & & \multicolumn{3}{|c|}{ P-ETF users } & \multicolumn{3}{|c|}{ non-users } & \multirow[b]{2}{*}{ Diff } \\
\hline & & Mean & Std Dev & $\mathrm{N}$ & Mean & Std Dev & $\mathrm{N}$ & \\
\hline \multicolumn{9}{|l|}{ Behavioral biases proxies } \\
\hline Overconfidence proxy & Dummy $=1$ if $\mathrm{STI}=1 \& \mathrm{UPS}=1$ & 0.072 & 0.258 & 3,484 & 0.105 & 0.306 & 22,656 & $-0.033^{* * *}$ \\
\hline Narrow framing proxy & Dummy $=1$ if $\mathrm{ATC}<=0$ & 0.561 & 0.496 & 3,484 & 0.574 & 0.494 & 22,656 & -0.014 \\
\hline Trade underdiversification & Dummy $=1$ if NDST $<=Q 1$ & 0.069 & 0.254 & 3,484 & 0.166 & 0.373 & 22,656 & $-0.097^{* * *}$ \\
\hline Portfolio weight underdiversification & Dummy $=1$ if $\mathrm{HHI}>=\mathrm{Q} 3$ & 0.137 & 0.334 & 3,484 & 0.276 & 0.447 & 22,656 & $-0.139^{* * *}$ \\
\hline Local bias ratio & (score between 0 \& 1 ) & 0.725 & 0.254 & 3,484 & 0.751 & 0.297 & 22,656 & $0.026^{* * *}$ \\
\hline
\end{tabular}

The table reports the cross-sectional mean, standard deviation, means difference and number of investors, with a distinction between P-ETF users and non-users. 'Underperformance on stocks' is a dummy variable which is equal to one if the investor's performance on stocks (Net excess Sharpe-ratio (\%), i.e. is the net Sharpe ratio in excess of market Sharpe ratio) is in the lower quartile of the sample, and zero otherwise. 'Overconfidence bias proxy' is a dummy variable which is equal to one if the investor shows both overtrading and underperformance, and zero otherwise. 'Narrow framing proxy' is a dummy variable which is equal to one if adjusted trade clustering (= trade clustering - mean trade clustering of the peer group) is less than zero, and zero otherwise. 'Trade Underdiversification' is a dummy variable which is equal to one if the number of different traded stocks during the sample period is in the lower quartile, and zero otherwise. 'Portfolio weight Underdiversification' is a dummy variable which is equal to one if the HHI (the sum of squared stock portfolio weights) is in the upper quartile, and zero otherwise. 'Local bias ratio' is computed as the number of trades in home and neighboring countries (France Netherlands, Germany and Luxembourg) stock trades) divided by the total number of trades over the sample period.*,**,*** indicate that the difference is statistically significant at the level of $10 \%, 5 \%$ or $1 \%$, respectively.

\section{Empirical results}

In order to test our hypotheses and analyze the determinants of retail investing in PETFs, we opt for a zero-inflated negative binomial (ZINB) model. ${ }^{21}$ This model allows us

\footnotetext{
${ }^{20}$ As showed in Table 5.

${ }^{21}$ The zero-inflated regression model was formally introduced by Lambert (1992).
} 
not only to focus on the probability for an investor to invest in P-ETFs, ${ }^{22}$ but also to explain the magnitude of retail investing in these products. The dependent variable of our ZNIB model is equal to the total number of trades on P-ETFs for each investor. ${ }^{23}$

The basic idea behind our ZINB model regression is that the decision to invest in P-ETFs and the positive counts of trades in P-ETFs are generated by separate processes. Our sample of retail investors indeed includes two distinct groups; we have a group of investors who do (not) invest in P-ETFs, and a group of investors who decide to invest in P-ETFs to a smaller or larger extent.

Suppose the base count density is the negative binomial distribution $f_{2}(y) .{ }^{24}$ To inflate the probability of a zero, we add a separate component, $\pi=f_{1}(0)$. Building on Cameron and Trivedi (2013), the ZINB model can then be specified as:

$$
P[y=j]= \begin{cases}\pi+(1-\pi) f_{2}(0), & \text { if } j=0 \\ (1-\pi) f_{2}(j), & \text { if } j>0\end{cases}
$$

where $y$ is the number of P-ETF trades, $j$ is any non-negative value, and the probability $\pi$ depends on a set of regressors in a binary logistic model. ${ }^{25}$

The ZINB model above can be viewed as a weighted mixture of two components, $\pi=f_{1}(0)$ and $f_{2}(y=0)$, used to predict the probability for $j=0$, i.e., the probability of belonging to the non-users group. The ZINB model is reduced to $(1-\pi) f_{2}(j)$ if the number of P-ETF trades is strictly positive, characterizing the probability of trading P-ETFs at least once.

Table 7 presents the results for three specifications of the ZINB model which always

\footnotetext{
${ }^{22}$ To examine whether a combination of behavioral factors impact the individual investor's use of mutual funds, Bailey et al. (2011) opt for a binary logistic model. This model is also used by Bhattacharya et al. (2017) to study the determinants of market participation in passive ETF by retail investors. In same sense, Müller and Weber (2010) choose a probit model to study the determinants of ETF/index fund awareness and choice.

${ }^{23}$ Since our dependent variable can take integer values (count data), one could think that Poisson regression models would be adequate. However, there is a dominance of zeros in our data. About $83 \%$ of retail investors in our database have no trade on P-ETFs, which would make the adoption of a Poisson regression inconsistent. The ZINB model is a modified Poisson regression model used to tackle two common issues in Poisson regressions for count data (e.g., Ridout et al. (1998); Sheu et al. (2004); Burger et al. (2009)). The first issue is over-dispersion in the sample, which means that the sample variance is larger than the sample mean, while the variance of the Poisson distribution must be equal to its mean. The second issue is related to an excess of zeros, i.e., there is an excessive number of observations equal to 0 (Greene, 2000).

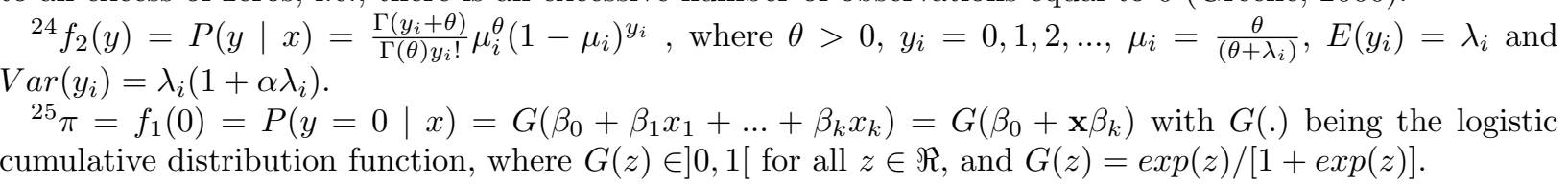


includes both the logit $\left(\pi=f_{1}(0)\right)$ and the negative binomial regression $\left(f_{2}(y)\right)$ components. They are based on 12,838 observations, each observation corresponding to one retail investor. All three specifications include the socio-demographic variables indicated in Panel A.

- Model 1 includes Panel A and all the subjective variables from the S-test (Panel B), in particular 'Financial markets products knowledge' which is directly related to hypotheses $\mathrm{H} 1 / \mathrm{H} 1 * .26$

- Model 2 complements Model 1 by adding four objective variables related to trading activity (Panel C): $\log ($ trade duration), $\log ($ number of stocks), the dummy for stock trading intensity, the dummy for underperformance on stocks, and log(trading experience) to which hypotheses $\mathrm{H} 2 / \mathrm{H}_{2}^{*}$ are directly related.

- Model 3 adds all the behavioral bias proxies (Panel D) to Model 2. The dummies 'Overconfidence', 'Narrow Framing', 'Trade (and portfolio weight) underdiversification', and 'Local bias' are all used to test $\mathrm{H} 3 / \mathrm{H}^{*}$, $\mathrm{H} 4 / \mathrm{H} 4 *$, H5/H5*, and $\mathrm{H} 6 / \mathrm{H} 6 *$, respectively.

A very important point regarding the interpretation of ZINB models is that the signs of the independent variable coefficients from the binary logistic equation are often in the opposite direction to the coefficients signs in the count (negative binomial) equation. This result makes sense since the logistic process is predicting the probability of not investing in P-ETFs, i.e. a negative coefficient implies a higher probability of being a P-ETF retail investor. In contrast, the negative binomial process predicts the number of P-ETF trades, i.e., a positive coefficient would indicate a higher magnitude of P-ETF retail investing (Long et al., 2006).

\subsection{The probability of retail investing in P-ETFs}

Results in Table 7 are consistent across the three model specifications. We therefore focus on identifying and interpreting the significant predictors in the logit component of the most

\footnotetext{
${ }^{26}$ Whether the A-test is instead considered in the regression analysis does not change the empirical conclusions regarding the tested hypotheses. The advantage of the S-test is the wider coverage in terms of the risk-return profile of the investor. The A-test strictly focuses on knowledge and awareness.
} 
Table 7: Modeling retail investing in P-ETFs using the ZINB model framework

\begin{tabular}{|c|c|c|c|c|c|c|c|c|c|c|c|}
\hline \multirow[b]{3}{*}{ Parameter } & \multicolumn{4}{|c|}{ Model 1} & \multicolumn{4}{|c|}{ Model 2} & \multicolumn{3}{|c|}{ Model 3} \\
\hline & \multicolumn{2}{|c|}{ Logit } & \multicolumn{2}{|c|}{ Negative Binomial } & \multicolumn{2}{|c|}{ Logit } & \multicolumn{2}{|c|}{ Negative Binomial } & \multicolumn{2}{|l|}{ Logit } & Negative Binomial \\
\hline & Coefficient & OR & Coefficient & IRR & Coefficient & OR & Coefficient & IRR & Coefficient & OR & $\begin{array}{ll}\text { Coefficient IRR } \\
\end{array}$ \\
\hline
\end{tabular}

Number of passive ETF trades

Independent variables

Panel A : Socio-demographic variables

Gender_male (Dummy)

Age (Years)

Higher education (Dummy)

Dutch language (Dummy)

English language (Dummy)

$\begin{array}{lllll}-0.001 & 0.999 & 0.059 & 1.061 & -0.004\end{array}$

$\begin{array}{lllll}-0.009^{* * *} & 0.992 & 0.021^{* * *} & 1.021 & 0.001\end{array}$

$\begin{array}{lllllll}0.055 & 1.056 & -0.118 & 0.888 & 0.120^{*} & 1.127 & -0.018 \\ -0.442^{* *} & 0.643 & 0.224 & 1.252 & -0.426^{* * *} & 0.653 & 0.453^{* * *}\end{array}$

Panel B : Subjective variables (S-test)

Financial markets 85 products knowledge (score 0-7) Expected yield on investments (score: $1-5$ )

Downside risk aversion (score 1-5)

Investment time horizon (score 2-11)

Wealth and financial situation (score 0-17)

Log(trading experience)

$\log ($ trade duration)

Log(number of stocks)

Stock trading intensity

Underperformance on stocks proxy

Panel C : Objective variables

$\begin{array}{llllllllllll}-0.287^{* * *} & 0.751 & 0.151^{* * *} & 1.163 & -0.244^{* * *} & 0.784 & 0.121^{* * *} & 1.128 & -0.242^{* * *} & 0.785 & 0.115^{* * *} & 1.122 \\ 0.066^{*} & 1.068 & -0.140^{* * *} & 0.870 & 0.084^{* *} & 1.088 & -0.148^{* * *} & 0.863 & 0.098^{* * *} & 1.103 & -0.140^{* * *} & 0.869 \\ 0.168^{* * *} & 1.182 & 0.088^{* *} & 1.092 & 0.144^{* * *} & 1.154 & 0.053 & 1.054 & 0.138^{* * *} & 1.148 & 0.044 & 1.045 \\ -0.078^{* * *} & 0.925 & 0.004 & 1.004 & -0.055^{* * *} & 0.947 & 0.032^{* *} & 1.033 & -0.053^{* * *} & 0.949 & 0.036^{* *} & 1.036 \\ -0.026^{* *} & 0.974 & -0.001 & 0.999 & -0.008 & 0.992 & 0.005 & 1.005 & -0.008 & 0.992 & 0.002 & 1.002 \\ \end{array}$

\begin{tabular}{llllllll}
$-0.233^{* * *}$ & 0.792 & $0.259^{* * *}$ & 1.295 & $-0.212^{* * *}$ & 0.809 & $0.341^{* * *}$ & 1.407 \\
0.020 & 1.021 & $-0.574^{* * *}$ & 0.563 & 0.034 & 1.035 & $-0.604^{* * *}$ & 0.547 \\
$-0.516^{* * *}$ & 0.597 & $-0.486^{* * *}$ & 0.615 & $-0.487^{* * *}$ & 0.614 & $-0.463^{* * *}$ & 0.630 \\
-0.143 & 0.867 & $-0.355^{* * *}$ & 0.701 & $-0.235^{* *}$ & 0.790 & $-0.420^{* * *}$ & 0.657 \\
0.045 & 1.046 & 0.078 & 1.081 & -0.091 & 0.913 & -0.008 & 0.993 \\
\hline
\end{tabular}

Panel D : Behavioral bias proxies

Overconfidence

Narrow framing

Trading underdiversification

Portfolio weight underdiversification

Local bias

$\alpha$ (dispersion)

N

$\%$ (Number of P-ETF trades $>0$ )

Log likelihood

AIC
BIC

\begin{tabular}{|c|c|c|c|c|c|c|c|}
\hline & & & & $\begin{array}{l}0.392^{* *} \\
-0.039 \\
-0.020 \\
0.140 \\
0.297^{* *}\end{array}$ & $\begin{array}{l}1.479 \\
0.962 \\
1.020 \\
1.150 \\
1.345\end{array}$ & $\begin{array}{l}0.257 \\
-0.015 \\
0.700^{* * *} \\
-0.031 \\
-0.308^{* *}\end{array}$ & $\begin{array}{l}1.293 \\
0.985 \\
2.014 \\
0.969 \\
0.735\end{array}$ \\
\hline $3.32^{\text {**** }}$ & 27.51 & $2.05^{* * *}$ & 7.81 & $2.00^{* * *}$ & 7.389 & & \\
\hline 12,838 & & 12,838 & & 12,838 & & & \\
\hline $16.68 \%$ & & $16.68 \%$ & & $16.86 \%$ & & & \\
\hline$-11,237$ & & $-10,929$ & & $-10,906$ & & & \\
\hline 22,520 & & 21,924 & & 21,897 & & & \\
\hline 22,691 & & 22,170 & & 22,218 & & & \\
\hline
\end{tabular}

\begin{tabular}{|c|c|c|c|c|c|c|c|}
\hline & & & & $\begin{array}{l}0.392^{* *} \\
-0.039 \\
-0.020 \\
0.140 \\
0.297^{* *}\end{array}$ & $\begin{array}{l}1.479 \\
0.962 \\
1.020 \\
1.150 \\
1.345\end{array}$ & $\begin{array}{l}0.257 \\
-0.015 \\
0.700^{* * *} \\
-0.031 \\
-0.308^{* *}\end{array}$ & $\begin{array}{l}1.293 \\
0.985 \\
2.014 \\
0.969 \\
0.735\end{array}$ \\
\hline $3.32^{* * *}$ & 27.51 & $2.05^{* * *}$ & 7.81 & $2.00^{* * *}$ & 7.389 & & \\
\hline 12,838 & & 12,838 & & 12,838 & & & \\
\hline $16.68 \%$ & & $16.68 \%$ & & $16.86 \%$ & & & \\
\hline$-11,237$ & & $-10,929$ & & $-10,906$ & & & \\
\hline 22,520 & & 21,924 & & 21,897 & & & \\
\hline 22,691 & & 22,170 & & 22,218 & & & \\
\hline
\end{tabular}

This table reports the results of three ZINB regressions, including both the logististic and negative binomial components. The dependent variable is a count variable equal to the number of passive ETF trades. The independent variables in italics are directly related to Hypotheses $\mathrm{H} 1 / \mathrm{H} 1$ * to $\mathrm{H} 6 / \mathrm{H} 6 *$. Panel A includes socio-demographic control variables. 'Gender' is a dummy variable equal to one if the investor is a male. 'age' as the difference between 2012 and the year of birth. 'Higher education' refers to the proportion of investors who declare that they hold a university degree or equivalent. 'English language' ('Dutch language') is a dummy equal to 1 when the investor chooses English (Dutch) as the main language on the online brokerage trading platform, and zero otherwise. Panel B includes subjective variables (S-test). All the scores are self-assessed by the investor. 'Financial market and products knowledge' is used to test $\mathrm{H} 1 / \mathrm{H} 1 *$ on financial knowledge. The other variables characterize the risk-return profile of the investor, i.e., 'Downside risk aversion', 'Investment time horizon', 'Wealth and financial situation', and 'Expected yield on investments' (assessed on a scale of five levels, with levels 1 to 5 corresponding respectively to 'a yield without any risk of capital loss', 'a yield of 2 to $4 \%$ per year', 'a yield of 5 to $7 \%$ per year', 'a yield of 8 to $12 \%$ per year', and 'a yield of more than $12 \%$ per year'). Panel $\mathrm{C}$ includes objective variables related to trading activity.'Log(trading experience') is used to test hypotheses $\mathrm{H} 2 / \mathrm{H}_{2} *$; it is computed as the natural log of the difference in number of months between the last trading date and the first trading date. "Log(Trade duration)" is computed as the natural log of the average number of days between two consecutive trades on stocks. 'Log(Number of stocks' is the natural log of the monthly average number of stocks held in the portfolio. 'Stock trading intensity' is a dummy variable which is equal to one when the investor's monthly portfolio turnover (i.e. the average absolute value of all the purchases and sales in a particular month divided by the average of the portfolio values at the beginning and the end of this particular month) is in the highest quartile of the investors' sample, and zero otherwise. 'Underperformance on stocks' is a dummy variable which is equal to one if the investor's performance on stocks (as estimated by the net excess Sharpe-ratio (\%), i.e., the net Sharpe ratio in excess of market Sharpe ratio) is in the lowest quartile of the full sample of investors, and zero otherwise. Panel D includes multiple behavioral bias proxies related to hypotheses H3/H3* to H6/H6*. 'Overconfidence bias' is a dummy variable which is equal to one if the investor trades intensively and underperforms, zero otherwise. 'Narrow framing' is a dummy variable which is equal to one if the adjusted trade clustering (= trade clustering - mean trade clustering of the peer group) is less than zero, and zero otherwise. 'Trading underdiversification' is a dummy variable which is equal to one if the number of different traded stocks during the sample period is in the lowest quartile, and zero otherwise. 'Portfolio weight underdiversification' is a dummy variable which is equal to one if the HHI (the sum of squared stock portfolio weights) is in the highest quartile, and zero otherwise. 'Local bias' is computed as the number of investor's home and neighboring countries (Belgium, France, Netherlands, Germany and Luxembourg) stock trades)/(total number of investor trades) over the sample period. 'IRR' is the incidence rate ratio which is equal to the exponential of the coefficient estimate. 'OR' is the odds ratio which is equal to the exponential of the coefficient estimate. *,**,*** indicate that the coefficient is statistically significant at the level of $10 \%, 5 \%$ or $1 \%$, respectively. 
complete Model 3. ${ }^{27}$

Regarding socio-demographics in Panel A, two dummies ('Higher education' and 'English language') impact significantly the probability of investing in P-ETFs. Those retail investors who hold a university degree are more likely to invest in P-ETFs. More precisely, the odds of not investing in P-ETFs for a retail investor who holds an university degree decrease by a meaningful factor of 0.772 , as compared with those who do not. All else equal, it means that retail investors who hold a university degree have 0.772 times higher chance of not investing in P-ETFs, as compared to those who do not. In other words, the odds of not investing in P-ETFs decreases by $22.8 \%$ for retail investors with a university degree, in comparison to those without. If retail investors without university degree are used as the reference group, it implies that their odds of not investing in P-ETFs increases by $29.5 \%(=1 / 0.772-1)$, as compared to those who hold a university degree. The odds ratio is even lower (at 0.681) when we consider the marginal effect of the language used on the platform. All else equal, the odds of not investing in P-ETFs decreases by $31.9 \%$ for retail investors who use English on the trading platform, as compared to those who use French. And vice versa, the odds of not investing in P-ETFs increases by $46.8 \%(=1 / 0.681-1)$ for retail investors who use French on the trading platform, as compared to those who use English. From Panel A, we conclude that retail investors who are more educated and speak (or are fluent in) English are more likely to invest in P-ETFs at the $1 \%$ significance level, all else equal.

In Panel B, four subjective variables (out of five) impact the probability of investing in PETFs significantly. We validate $\mathbf{H 1}$ regarding the relationship between financial knowledge and the probability of investing in P-ETFs for retail investors: the coefficient estimate of 'Financial markets products knowledge' is indeed negative and statistically significant at $1 \%$. The odds ratio is below 1 and indicates that the odds of not investing in P-ETFs decreases by $21.5 \%$ for retail investors who score a notch better in terms of their self-assessed level of financial knowledge. Three other subjective variables characterizing the investor risk-return profile exhibit insightful coefficients as well. A higher 'expected yield on investments' by

\footnotetext{
${ }^{27}$ The overdispersion parameter $\alpha$ estimated (2.00) is statistically significant at the $1 \%$ level for the three ZINB models, which provides strong evidence to opt for a negative binomial model over a Poisson model. Regarding the goodness of fit of Model 3, Table 7 shows that the model fit is improved, with the log likelihood increasing (by 345 between Model 1 and 3) for each additional group of independent variables. Also, Model 3 displays the lowest $\mathrm{AIC}$ and $\mathrm{BIC}$ values.
} 
one score unit leads to a higher probability of not investing in P-ETFs. In other words, the higher the return targeted by retail investors, the less likely they invest in P-ETFs. All else equal, it means that retail investors who target higher returns by one score unit have 1.103 times higher chance of not investing in P-ETFs, as compared with those who do not. Regarding 'downside risk aversion', we observe that the more risk averse the retail investors are, the less likely they invest in P-ETFs. All else equal, retail investors who display higher downside risk aversion by one score unit have 1.148 times higher chance of not investing in P-ETFs, as compared with those who do not. Interestingly, a one unit increase in the score of 'Investment time horizon' decreases the retail investor's odds of not investing in P-ETFs by a factor of 0.949. From Panel B, we conclude that the retail investors who are more likely to invest in P-ETFs are those who are more financially knowledgeable, require lower returns (for a given level of risk), are less risk averse (for a given level of expected return), and declare a longer investment horizon, all else equal.

In Panel $\mathrm{C}$ of Table 7, the coefficient of 'trading experience' (in log) is significant and exhibits a negative sign. ${ }^{28}$ We therefore validate $\mathbf{H 2}$ on the positive relationship between trading experience and the probability of investing in P-ETFs. All else equal, the odds of not investing in P-ETFs decrease by $19.1 \%$ for retail investors whose trading experience is twice as high as compared with the control group. Two other objective measures of trading activity are significant as well. All else equal, the 'number of stocks' held on average in portfolio is positively associated with the probability of investing in P-ETFs, since the odds ratio is equal to 0.614 . This is also the case for 'stock trading intensity'. Those retail investors who trade stocks intensively are more likely to invest in P-ETFs: the odds ratio of not investing in P-ETFs for an investor who trades stocks intensively decreases by a factor of 0.79. From Panel C, we learn that the retail investors who are more likely to invest in P-ETFs are those who are more experienced, hold a larger number of different stocks in their portfolio, and trade them more intensively (ceteris paribus).

When it comes to analysing behavioral biases, Panel D in Table 7 shows that two of them emerge as significant drivers of the probability of investing in P-ETFs. 'Overconfidence' and

\footnotetext{
${ }^{28}$ Based on Glaser and Weber (2009) we use the natural logarithm of the trading experience, the trade duration, the average number of stocks held in portfolio and the turnover, since these variables are positively skewed.
} 
'local bias' negatively affect the chance for a retail investor to trade P-ETFs. We therefore validate $\mathbf{H 3}$ and $\mathbf{H 6}$. When retail investors are overconfident, their odds of not investing in P-ETFs increases by $47.9 \%$. This is in line with Bailey et al. (2011), who find that even though overconfident investors have higher allocations in mutual funds, they have smaller proportion of their equity portfolio invested in index funds, because they focus more on actively managed funds. Now when retail investors invest (exclusively) locally, their odds of not investing in P-ETFs also increase, by a slightly lower percentage equal to $34.5 \%$. We do not find any conclusive evidence regarding $\mathbf{H} 4$ et $\mathbf{H 5}$. From Panel D, we conclude that the retail investors who are less likely to invest in P-ETFs are those who are overconfident and invest locally.

\subsection{The magnitude of P-ETF investing}

While the logit component of the ZINB model is estimated on the full sample of retail investors including those who do not trade ETFs, the sample of retail investors considered in the negative binomial component of the ZNIB model is more restricted. The negative binomial component is estimated on the subsample of retail investors who do trade P-ETFs, which corresponds to $16.88 \%$ of all the retail investors in the full sample. The main question that we address in this section is whether the same factors drive the decision to trade more P-ETFs, considering exclusively the retail investors who do trade them.

In Panel A of Table 7, we find that education and the use of English are again significant determinants. All else equal, they are both positively correlated with the magnitude of PETF retail investing: their respective coefficient estimates are positive and their Incidence Rate Ratios (IRR) are greater than $1 .^{29}$ It means that P-ETF users who hold a university degree complete $17.5 \%$ more P-ETF transactions on average than those who do not hold such a degree. Regarding the dummy variable 'English language', the IRR indicates that P-ETF trades completed by P-ETF retail investors who use English on the platform, are

\footnotetext{
${ }^{29}$ The odds ratio is only appropriate when the dependent variable is a dummy variable. The Incidence Rate Ratio (IRR) is the equivalent measure in the negative binomial regression where the dependent variable takes any non-negative values. The IRR corresponds to the exponential of the coefficient estimate and measures the estimated percentage change in the number of P-ETF trades for each unit variation in the explanatory variable. For example, IRR $=2$ means that the estimated number of the dependent variable doubles for each unit increase in the explanatory variable.
} 
on average $45.7 \%$ higher than trades completed by P-ETF users who use French. Age is also influential in determining the number of P-ETF trades. When age increases by 1 year, P-ETF trades are estimated to increase by 1.01\%. From Panel A, we conclude that the importance of P-ETF retail investing is stronger when retail investors are more educated, use English, and are older.

In Panel $\mathrm{B}$, we see that the magnitude of $\mathrm{P}-\mathrm{ETF}$ investing responds to the same three (out of four) determinants identified in the logistic regression. First, we validate $\mathbf{H} \mathbf{1}^{*}$ since the coefficient estimate of the 'Financial markets \& products knowledge' variable is positive and significant. P-ETF trades completed by P-ETF retail users increases by $12.2 \%$ for each score unit increase in financial knowledge, which is economically sizeable. Second, the expected number of P-ETF trades increases when retail investors have longer investment time horizons: for each score unit increase in 'Investment time horizon objectives', the estimated number of P-ETF trades increases by 3.6\%. Third, P-ETF retail investors who target higher yields are expected to complete a lower number of P-ETF trades: for each score unit increase in 'Expected yield on investments', the expected number of P-ETF trades decreases by a sizeable factor of 0.869. From Panel B, we draw the conclusion that P-ETF retail users who have better financial knowledge, longer investment horizons, and lower yield expectations, are more active P-ETF investors.

Panel $\mathrm{C}$ in Table 7 reveals that P-ETF investors who are more experienced trade PETFs more actively. More precisely, the number of P-ETF trades is estimated to increase by 40.7\% when trading experience (measured in months) doubles. Hypothesis $\mathbf{H} 2 *$ is therefore validated. There are three other determinants which negatively influence the magnitude of P-ETF retail investing. When P-ETF retail users hold a low number of stocks that they trade in quick succession in a stock portfolio whose turnover is not high, they are more likely to trade P-ETFs more often. A trade-off seems to exist between the magnitude of P-ETF investing and the magnitude of stock investing. Not only P-ETF users who trade ETFs more actively hold a lower number of stocks but they also modify the composition of their stock portfolio less extensively. This points to a substitution effect between stocks and P-ETFs.

In panel $\mathrm{D}$, we observe that the local bias is the only behavioral bias that decreases both the probability and the magnitude of investing in P-ETFs. More specifically, trading activity 
in P-ETFs is $26.5 \%$ (i.e. 1 minus 0.735 ) lower for P-ETF users who suffer from the local bias, as compared with those who do not. Hypothesis $\mathbf{H}^{*}$ is therefore validated. We nevertheless reject hypothesis $\mathbf{H} 5^{*}$, albeit partially, from the perspective of underdiversification in stock trading only (and not in terms of portfolio weights). All else equal, the number of P-ETF trades increases by $101.4 \%$ when P-ETF investors concentrate their stock trading heavily on a few stocks (as compared with those who do not). This is perfectly in line with the findings in Panel C regarding the substitution effect between stocks and P-ETFs. This is also in accordance with Bellofatto et al. (2018), who find that investors with higher financial literacy tend to concentrate their stock portfolio more extensively and achieve diversification through investment funds holdings. Finally, there is insufficient evidence to draw any conclusion about hypotheses $\mathbf{H} \mathbf{3}^{*}$ and $\mathbf{H} \mathbf{4}^{*}$. Interestingly, there is no statistically meaningful difference in overconfidence between heavy and light P-ETF users.

\section{Conclusion}

This paper investigates the determinants of retail investing in passive Exchange Traded Funds (P-ETFs) using survey data as well as trading data on a sample of 26,140 retail investors over the January 2003-March 2012 period.

Our results may be related to the findings of Bhattacharya et al. (2017) who focus on German retail investors, and those of Müller and Weber (2010) and Enete et al. (2018) who focus on U.S. retail investors. We contribute to the literature by better profiling P-ETF retail investors. In comparison to mere survey data, the use of the two MiFID questionnaires (A-test \& S-test) improves the reliability of our results since retail clients must give relevant answers to their MiFID tests in order to get suitable advice and financial products from the broker. Combined with trading data, we consider a large number of investor's characteristics clustered in socio-demographic, objective, subjective and behavioral variables. We test several hypotheses through the use of the Zero-Inflated Negative Binomial (ZINB) model, which allows us to identify the determinants of both the probability and the magnitude of investing in P-ETFs.

P-ETF retail investors are better educated, more financially knowledgeable, less risk 
averse (for a given level of expected return), target lower returns (for a given level of risk), declare a longer investment horizon, hold a larger number of different stocks in their portfolio, trade these stocks more intensively, and are less subject to overconfidence and the local bias (as compared with retail investors who do not hold P-ETFs).

We identify similar determinants when we zoom in on the subsample of P-ETF users in order to study the extent to which they trade these products. Higher education, the use of English, better financial knowledge, longer investment horizons, lower return expectations, stronger financial experience, and the absence of the local bias; all these factors boost the magnitude of P-ETF investing. We nevertheless do not find any statistically meaningful difference in overconfidence between light and heavy P-ETF users. Most interestingly, a trade-off seems to exist among P-ETF users between the magnitude of their P-ETF investing and the magnitude of their stock investing. The users who trade P-ETFs more actively hold a lower number of stocks and modify the composition of their stock portfolio less extensively. This points to a substitution effect between stocks and P-ETFs as trading in P-ETFs increases. We conjecture that the most active P-ETF users hold portfolios in which P-ETFs increasingly become the core and stocks increasingly become the satellite. Further research is clearly needed to compare the composition and performance of portfolios held by light and heavy P-ETF users. 


\section{Appendix}

Table 8: The ten most traded P-ETFs in the sample

\begin{tabular}{llrr}
\hline ETF & Underlying & Number trades & Volume trades \\
\hline LYXOR ETF BEL 20 & Equity & 2,348 & $11,646,158.95$ \\
GOLD BULLION SEC & Commodities & 1,607 & $31,304,732.32$ \\
US NAT GAS FD ETF & Commodities & 1,015 & $5,315,626.30$ \\
U.S. OIL FUND ETF & Commodities & 925 & $8,357,962.81$ \\
ETF BRA IBOVESPA LYX & Equity & 890 & $5,724,898.89$ \\
LYXOR ETF CHINA ENT. & Equity & 809 & $11,547,219.10$ \\
LYXOR ETF CAC 40 & Equity & 784 & $12,794,247.82$ \\
LYXOR ETF DJ ES 50 & Equity & 738 & $11,870,854.82$ \\
ETFS NATURAL GAS & Commodities & 599 & $4,219,940.55$ \\
LYXOR ETF MSCI INDIA & Equity & 582 & $5,449,180.23$ \\
Other ( 303 passive ETF) & - & 12,079 & $92,588,179.85$ \\
\hline Total & & 22,376 & $200,819,001.6$
\end{tabular}

This table reports the underlying, the number of trades and the volume of trades (in EUR) of the 10 most traded P-ETFs in the sample.

Table 9: The shares of P-ETFs by asset class

\begin{tabular}{|c|c|c|c|c|}
\hline Asset Class & Number of trades & Share in $\%$ & Volume of trades & Share in $\%$ \\
\hline Equity & 15,400 & $68.82 \%$ & $126,556,606$ & $63.02 \%$ \\
\hline Commodities & 6,495 & $29.03 \%$ & $68,864,936$ & $34.29 \%$ \\
\hline Bonds & 378 & $1.69 \%$ & $4,553,736$ & $2.27 \%$ \\
\hline Real estate & 103 & $0.46 \%$ & 843,724 & $0.42 \%$ \\
\hline Total & 22,376 & $100.00 \%$ & $200,819,002$ & $100.00 \%$ \\
\hline
\end{tabular}




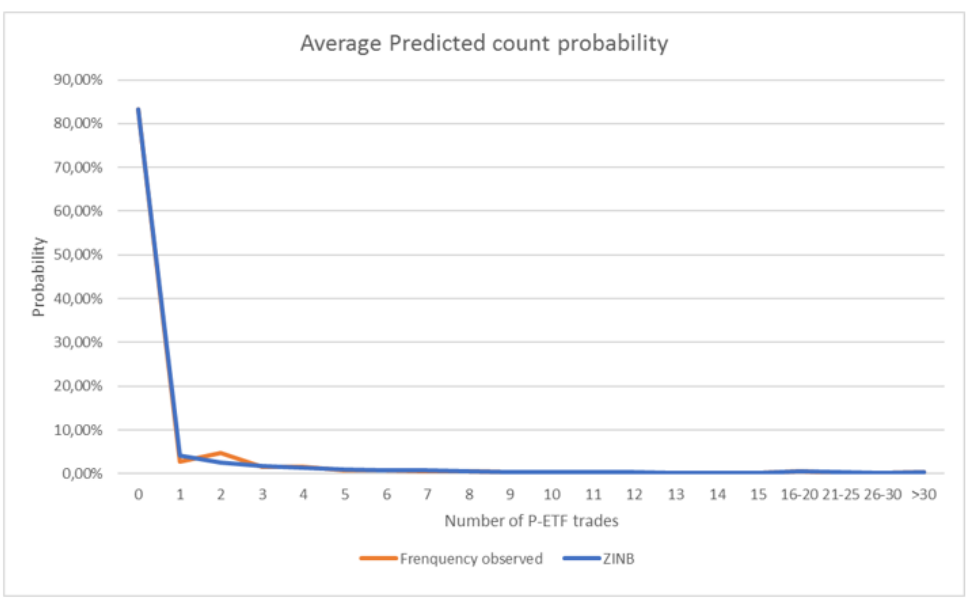

Figure 1: Observed and estimated probabilities of the number of P-ETF trades. 


\section{References}

Alexander, G. J., J. D. Jones, and P. J. Nigro (1998). Mutual fund shareholders: Characteristics, investor knowledge, and sources of information. Financial Services Review 7(4), $301-316$.

Babiarz, P. and C. A. Robb (2014). Financial literacy and emergency saving. Journal of Family and Economic Issues 35(1), 40-50.

Bailey, W., A. Kumar, and D. Ng (2011). Behavioral biases of mutual fund investors. Journal of Financial Economics 102(1), 1-27.

Baker, H. K. and J. R. Nofsinger (2002). Psychological biases of investors. Financial services review $11(2), 97$.

Barber, B. M. and T. Odean (2000). Trading is hazardous to your wealth: The common stock investment performance of individual investors. The journal of Finance 55(2), 773-806.

Barber, B. M. and T. Odean (2001). Boys will be boys: Gender, overconfidence, and common stock investment. The quarterly journal of economics 116(1), 261-292.

Barber, B. M., T. Odean, and L. Zheng (2005). Out of sight, out of mind: The effects of expenses on mutual fund flows. The Journal of Business 78(6), 2095-2120.

Bellofatto, A., C. DHondt, and R. De Winne (2018). Subjective financial literacy and retail investors behavior. Journal of Banking \& Finance 92, 168-181.

Bhattacharya, U., B. Loos, S. Meyer, and A. Hackethal (2017). Abusing etfs. Review of Finance 21(3), 1217-1250.

Boone, N. M. and L. S. Lubitz (2004). Creating an Investment Policy Statement: Guidelines E Templates. AdvisorPress.

Boyle, P., L. Garlappi, R. Uppal, and T. Wang (2012). Keynes meets markowitz: The trade-off between familiarity and diversification. Management Science 58(2), 253-272. 
Burger, M., F. Van Oort, and G.-J. Linders (2009). On the specification of the gravity model of trade: zeros, excess zeros and zero-inflated estimation. Spatial Economic Analysis 4(2), $167-190$.

Camerer, C. and D. Lovallo (1999). Overconfidence and excess entry: An experimental approach. American economic review 89(1), 306-318.

Cameron, A. C. and P. K. Trivedi (2013). Regression analysis of count data, Volume 53. Cambridge university press.

Capon, N., G. J. Fitzsimons, and R. A. Prince (1996). An individual level analysis of the mutual fund investment decision. Journal of financial services research 10(1), 59-82.

Carpentier, C. and J. Suret (2011). La rationalit des dcisions des investisseurs. Rapport prpar pour le compte de lAutorit des marchs financiers et du Ministre des finances du Qube.

Choueifaty, Y. and Y. Coignard (2008). Toward maximum diversification. Journal of Portfolio Management 35(1), 40.

Courchane, M. and P. Zorn (2005). Consumer literacy and credit worthiness. In Federal Reserve System Conference, Promises and Pitfalls: as consumer options multiply, who is being served and at what cost.

Davydov, D., O. Florestedt, J. Peltomäki, and M. Schön (2017). Portfolio performance across genders and generations: The role of financial innovation. International Review of Financial Analysis 50, 44-51.

De Bondt, W. F. and R. H. Thaler (1995). Financial decision-making in markets and firms: A behavioral perspective. Handbooks in operations research and management science 9 , $385-410$.

D'Hondt, C. and P. Roger (2017). Investor sentiment and stock return predictability: The power of ignorance. Finance 38(2), 7-37.

Domian, D. L., D. A. Louton, and M. D. Racine (2007). Diversification in portfolios of individual stocks: 100 stocks are not enough. Financial Review 42(4), 557-570. 
Enete, S., M. Reiter, W. Usrey, A. Scott, and M. Seay (2018). Characteristics of etf owners: Exploring the role of investor knowledge, fee aversion, and financial advice seeking. Fee Aversion, and Financial Advice Seeking (September 30, 2018).

Evans, J. L. and S. H. Archer (1968). Diversification and the reduction of dispersion: an empirical analysis. The Journal of Finance 23(5), 761-767.

Feng, L. and M. S. Seasholes (2005). Do investor sophistication and trading experience eliminate behavioral biases in financial markets? Review of Finance 9(3), 305-351.

Fischoff, B. (1982). For those condemned to study the past: Heuristics and biases in hindsight. Judgment under uncertainty: Heuristics and biases, 335-351.

Gaudecker, H.-M. V. (2015). How does household portfolio diversification vary with financial literacy and financial advice? The Journal of Finance 70(2), 489-507.

Glaser, M. and M. Weber (2009). Which past returns affect trading volume? Journal of Financial Markets 12(1), 1-31.

Goetzmann, W. N. and A. Kumar (2008). Equity portfolio diversification. Review of Finance 12(3), 433-463.

Greene, W. H. (2000). Econometric analysis (international edition).

Hilgert, M. A., J. M. Hogarth, and S. G. Beverly (2003). Household financial management: The connection between knowledge and behavior. Fed. Res. Bull. 89, 309.

Hoffmann, A. O., T. Post, and J. M. Pennings (2013). Individual investor perceptions and behavior during the financial crisis. Journal of Banking \& Finance 37(1), 60-74.

Kelly, M. (1995). All their eggs in one basket: Portfolio diversification of us households. Journal of Economic Behavior \&3 Organization 27(1), 87-96.

Koestner, M., B. Loos, S. Meyer, and A. Hackethal (2017). Do individual investors learn from their mistakes? Journal of Business Economics 87(5), 669-703. 
Kumar, A. (2009). Who gambles in the stock market? The Journal of Finance 64(4), $1889-1933$.

Kumar, A. and S. S. Lim (2008). How do decision frames influence the stock investment choices of individual investors? Management science 54(6), 1052-1064.

Lambert, D. (1992). Zero-inflated poisson regression, with an application to defects in manufacturing. Technometrics 34(1), 1-14.

Liu, Y.-J., M.-C. Wang, and L. Zhao (2010). Narrow framing: Professions, sophistication, and experience. Journal of Futures Markets: Futures, Options, and Other Derivative Products 30(3), 203-229.

Long, S. J., J. S. Long, and J. Freese (2006). Regression models for categorical dependent variables using Stata. Stata press.

Lusardi, A. and O. Mitchell (2007). Financial literacy and retirement planning: New evidence from the rand american life panel.

Lusardi, A. and O. S. Mitchell (2011). Financial literacy around the world: an overview. Journal of Pension Economics $\mathscr{G}$ Finance 10(4), 497-508.

Lyons, A. C., L. Palmer, K. S. Jayaratne, and E. Scherpf (2006). Are we making the grade? a national overview of financial education and program evaluation. Journal of Consumer Affairs 40(2), 208-235.

Markowitz, H. (1952). Portfolio selection. The journal of finance 7(1), 77-91.

Massa, M. and A. Simonov (2006). Hedging, familiarity and portfolio choice. The Review of Financial Studies 19(2), 633-685.

Moore, D. A. and P. J. Healy (2008). The trouble with overconfidence. Psychological review $115(2), 502$.

Müller, S. and M. Weber (2010). Financial literacy and mutual fund investments: who buys actively managed funds? Schmalenbach Business Review 62(2), 126-153. 
Nicolosi, G., L. Peng, and N. Zhu (2009). Do individual investors learn from their trading experience? Journal of Financial Markets 12(2), 317-336.

Odean, T. (1999). Do investors trade too much? American economic review 89(5), 12791298.

Polkovnichenko, V. (2005). Household portfolio diversification: A case for rank-dependent preferences. The Review of Financial Studies 18(4), 1467-1502.

Ramiah, V., X. Xu, and I. A. Moosa (2015). Neoclassical finance, behavioral finance and noise traders: A review and assessment of the literature. International Review of Financial Analysis 41, 89-100.

Ridout, M., C. G. Demétrio, and J. Hinde (1998). Models for count data with many zeros. In Proceedings of the XIXth international biometric conference, Volume 19, pp. 179-192. International Biometric Society Invited Papers. Cape Town, South Africa.

Sheu, M.-l., T.-w. Hu, T. E. Keeler, M. Ong, and H.-Y. Sung (2004). The effect of a major cigarette price change on smoking behavior in california: a zero-inflated negative binomial model. Health Economics 13(8), 781-791.

Singh, R. (2010). Behavioural finance studies: Emergence and developments. Journal of Contemporary Management Research 4 (2).

Van Rooij, M., A. Lusardi, and R. Alessie (2011). Financial literacy and stock market participation. Journal of Financial Economics 101(2), 449-472.

Wang, A. (2011). Younger generations' investing behaviors in mutual funds: Does gender matter? The journal of wealth management 13(4), 13. 